\title{
Legal Deposit of Electronic Books - A Review of Challenges Faced by National Libraries
}

Marietjie de Beer

Department: Information Science, University of Pretoria, Pretoria marietjie.debeer930@gmail.com

Marieta van der Merwe1 Pretoria, Pretoria

\section{Liezl Ball}

Department: Information Science, University of Pretoria, Pretoria liezl.ball@up.ac.za

Ina Fourie

Department: Information Science, University of Pretoria, Pretoria ina.fourie@up.ac.za

\section{Introduction}

Legal deposit of knowledge artefacts such as books and journals creates a collection of the national literature and so is an important mechanism to preserve the cultural heritage of a nation (Muir, 2001; Zivkovic, 2008; Green, 2009).

Legal deposit processes for printed material has been established for centuries [1]. However, the same processes are not necessarily applicable in the case of non-print material such as electronic books. Legal deposit of electronic publications is subject to numerous, often unique challenges such as the legal deposit process, legal issues and infrastructure required. Some of these have been reported on (Muir, 2001; HockxYu, 2006), while many issues are only scantily covered in the subject literature. Literature reviews have been published about specific issues such as electronic books (Kumbhar, 2012), library digitisation issues (Lopatin, 2006), digital preservation management in Eastern Africa (Mutala, 2014), digital library research including organisational and people issues (Liew, 2009), and multilinguality in digital libraries (Diemeka, 2012). Only Muir compiled a literature review specifically about legal deposit and preservation of digital publications (Muir, 2001).

To the best of our knowledge, this paper is the first attempt to follow in the footsteps of Muir (2001), by exploring the literature to report on the legal deposit of electronic books and specifically the challenges faced by national libraries.

\subsection{Problem statement and list of sub problems}

Legal depositories and in particular national libraries face many challenges with regards to the collection, preservation and accessibility of electronic publications - especially electronic books received on legal deposit. In order for national libraries to formulate policies and guidelines to deal with the legal deposit of electronic books the question arises:

What has been reported on dealing with the legal deposit of electronic books that can guide national libraries in facing the challenges of managing a legal depository for electronic books?

This will be answered by considering the following sub-questions: 
- What has been reported on dealing with the legal deposit of electronic books since the literature review of Muir (2001)?

- Which key challenges must be focused on?

- Which recommendations can be made for future research and monitoring?

\subsection{Background}

Responsibility for the management of published material received on legal deposit is the domain of national libraries and other legal deposit repositories which might be bound by legislation to collect, document, preserve and make accessible all published material produced by a country (Larivière, 2000; Stephens and Gibby, 2011). According to the IFLA Statement on Legal Deposit, national libraries are typically responsible for legal deposit, although other institutions such as public- and university libraries may also function as legal depositories (Ibrahim and Edzan, 2004; Bhatti, 2014). There are 245 national- and state libraries in the world [2], of which 62 have legal deposit legislation or participate in legal deposit activities [3].

Published material or publications consist of traditional printed text material and non-printed material. In the context of legal deposit the latter term is generally used in the broadest sense (Matuvo and Musoke, 2012). For non-print material, the terms electronic publications, e-publications or e-pubs are used, and includes text, images, audio, sound and other machine readable files.

Many arguments can be found on the importance of legal depository: it is important to provide citizens as well as researchers (within the country as well as abroad) with access to a research collection of the country's published material, it supports the compilation of authoritative national bibliographies, it supports bibliographic control and it makes it possible to monitor growth of the publishing industry (Larivière, 2000).

In many countries legal deposit of printed material is well established. Depending on the legislative framework of each country, publishers send multiple copies of printed material to legal deposit repositories where it is documented through bibliographic descriptive records. The books are physically safeguarded in stacks from where it is retrieved upon request by users who identify the books from the library catalogue (currently referred to as the library management system).

Electronic publications have many unique challenges. Physical storage, long-term preservation and longterm access, protection of copyright, and metadata beyond basic bibliographic description are some of the many issues of concern (Moghaddam, 2010; Mutula, 2014). It is of vital importance that electronic publications, and in particular electronic books (or e-books, ebooks), be collected and preserved by legal depositories, because apart from the same reasons that apply to printed books, electronic books may disappear from book markets much faster, e.g. by being erased from the internet (Woodyard, 2004) or by having the web site providing access, change or disappear (Spence, 2005). The ability to self-publish 
electronically resulted in a proliferation of electronic books that cannot be harvested through the usual agreements as with commercial publishers (Brantley, 2012).

Rapid technological developments since the 1980's have opened opportunities for the proliferation of digital collections and electronic repositories for storage, access and preservation, all of which require specialist technical knowledge. Stephens and Gibby (2011) reported in 2011 to the Conference of Directors of National Libraries (CDNL) on the current state of legal deposit in 35 European countries and the United States of America (USA), concluding that electronic legal deposit (also referred to as e-legal deposit) has been fully accepted as a term and practice and is well established within legislative frameworks and on a voluntary basis. Muir asserted in 2001 that "national and other deposit libraries are at the forefront of research and development in [digital collections management], often in partnership with other libraries, publishers and technology vendors." (Muir, 2001). Examples include the Canadian Initiative on Digital Libraries (CIDL), British Library Partnership and Collaboration Programme (Beagrie, 2001), the partnership between the United States Government Printing Office and Federal Depository Libraries for the preservation of digital publications (Walsh, 2008), the development of the National Digital Library (BND) of Portugal through alliances with external partners (Borbinha, 2004), Switzerland's cooperation with the Library Network of Western Switzerland (RERO) (Clavel-Merrin, 2010), and Finland's development of the public interface service (Finna) (Hormia-Poutanen, Kautonen and Lassila, 2013).

The management of electronic books poses specific problems and unique challenges which differ from the issues surrounding the management of electronic journals and online publications such as newspapers, blogs, wikis and websites. National libraries which have not yet embarked on a legal deposit management programme can benefit from guidance on the processes, challenges and solutions that are noted in the subject literature on electronic publications and specifically electronic books. This includes the infrastructure and policies (e.g. Kumbhar, 2012). Especially developing countries such as African countries can benefit from the research already done, bypassing the costly exercise of breaking new ground and focusing energy and resources on their own unique challenges such as poor telecommunication infrastructures and inadequate ICT training for staff members (e.g. Wamuloya and Mutula, 2005). Even national libraries with established programmes can benefit due to the renewed interest in legal deposit of electronic publications sparked by technological developments (e.g. Brantley, 2012).

\subsection{Clarification and contextualization of concepts}

The term digital is sometimes used interchangeably with electronic, and electronic is sometimes abbreviated to $e$-. For the purpose of this paper it is important to clarify the following concepts: legal deposit, electronic publications, and electronic books.

Legal deposit: According to the UNESCO Guidelines for legal deposit legislation, legal deposit is defined as "a statutory obligation which requires that any organization, commercial or public, and any individual 
producing any type of documentation in multiple copies, be obliged to deposit one or more copies with a recognized national institution" (Larivière, 2000, p. 3). Thus any type of library material falls into the legal deposit definition, as long as it is made available to the public, and is produced in more than one copy (Larivière, 2000). The territoriality (i.e. the place of publication) implied in definitions for legal deposit raises questions about geographic limitations, due to an emerging trend to publish online (Gibby and Brazier, 2012), and because "networks transcend national borders" (Muir, 2001, p.653).

Traditionally the legal deposit acts of some countries alluded only to printed material, but technological advances required the legal deposit acts to be changed to incorporate non-print material, including electronic books, as well. The Bodleian Libraries refer to this process as "electronic legal deposit" (Gibby and Brazier, 2012).

Electronic publication(s): Mackenzie, Owen and Walle (as cited in Muir, 2001, p. 656) define electronic publications as "published documents which are produced, distributed stored and used in electronic form". In the context of this review, the focus within this broader definition is on electronic books, not electronic journals, -theses, -dissertations, and -government publications, or other non-print material such as images (e.g. photographs, maps), audio (e.g. music), audio-visual material (e.g. video clips with sound recording), or multimedia (e.g. learning kits).

Electronic book(s): In the literature electronic books are used interchangeably with e-books or ebooks. For the purpose of this review the term electronic books will be used, except when it appears as e-books or ebooks in a direct quotation. Various definitions can be found for electronic books. These range from explaining electronic books as having different meanings ranging from a digital object (or collection of objects) designed to be read (or listened to) on a special device, a digital object (or collection of objects) that can be read with special software on a PC, to any linear digital text that can be read on a computer (Zivkovic, 2008).

Vassiliou and Rowley (2008, p. 363) researched the definition of "e-book" and proposed a two-part definition:

"(1) An e-book is a digital object with textual and/or other content, which arises as a result of integrating the familiar concept of a book with features that can be provided in an electronic environment.

(2) E-books, typically have in-use features such as search and cross reference functions, hypertext links, bookmarks, annotations, highlights, multimedia objects and interactive tools."

Bothmann (2004. p.12) provides a succinct definition, namely that "electronic books are nonserial monographic resources accessed with a computer either directly or remotely". The authors propose a slight modification on this: electronic books are nonserial monographic digital resources with in-use 
features typical of an electronic environment, accessed either directly or remotely with an electronic device such as a computer, e-reader or tablet.

\section{Purpose, scope and approach}

The paper is based on a review of the subject literature published between 2000 to May 2014; it is, however, not presented here as a formal literature review. The intention with this paper is merely to present a spectrum of the challenges noted that national libraries face in dealing with the legal deposit of electronic books. As Muir (2001, p. 652), puts it: "not all management issues or users' needs are being addressed". Our intention is to highlight such issues reported since the work of Muir (2001). Although many articles were noted on the general challenges regarding management of electronic publications (e.g. Muir, 2001; Borbinha, 2004; Zivkovic, 2008; Green, 2009; Moghaddam, 2010), and although much can be learned from these, this paper does not consider electronic journals and other non-print material, because it has its own specific problematic issues such as physical ownership versus subscribed access via licence agreements (Ayre and Muir, 2004, p.4). The focus is on electronic books.

When initially selecting publications to inform this paper, it was noted that certain regions are underrepresented in the literature on the legal depository of electronic books. Various factors, such as political instability, lack of funding, poor infrastructure, etc. might have contributed to a lack of representation from the Middle East (Moghaddam, 2010; Bhatti, 2014), Africa (Lor, 2005; Nsibirwa, Hoskins and Stillwell, 2014) and other developing nations (Chowdury, 2013). Language as a barrier to communication might also have contributed to the limited representation from Eastern Europe (e.g. Croatia, Poland, Romania, and Russia) (Zivkovic, 2008; Krynicka, 2012), and Asian countries (Yoon, Oh and Kim, 2008). Europe was well represented with articles from traditionally non-English speaking countries such as Finland, France, Greece, Sweden, and The Netherlands (e.g. Witt, 2003; Vattulainen, 2004; Saarti and Vattulainen, 2013; HormiaPoutanen, Kautonen and Lassila, 2013). Mainstream literature covered US-based (US and Canada) perspectives to a large extent (e.g. Caplan, 2004; Lopatin, 2006; Krishnamurthy, 2008; Liew, 2009; Kumbhar, 2012). Digital library research done in 2009, indicate that most research came from the North American region including Canada, and very little form Latin America (Liew, 2009).

\section{Discussion of challenges faced by national libraries regarding legal deposit of electronic books}

Based on experience in the National Library of South Africa (Authors De Beer and Van der Merwe), the CDNL E-legal Deposit Advocacy Pack, and a review of the subject literature since the publication by Muir (2001) the authors have identified the following main aspects of the legal deposit of electronic books that are particularly difficult to implement and manage by national libraries: legal deposit legislation and institutional policy, other legal considerations such as copyright, environmental factors, establishing mechanisms for deposit, information retrieval and access, preservation, human resources, financial implications and addressing issues of trust. 


\subsection{Legal deposit legislation and institutional policy}

A legal and regulatory framework for legal deposit is like a double-edged sword: on the one hand it enables the legal depositories to enforce compliance with legislation by the publishers (Nsibirwa, Hoskins and Stilwell, 2014). On the other hand it also puts especially national libraries under pressure to comply with the legislation to collect, preserve and make available the nation's cultural heritage. They often experience problems regarding funding, lack of infrastructure, human resources capacity and support from government (Mutula, 2014).

National libraries must not depend solely on government support for legislation, because of political priorities (Gibby and Brazier, 2012). They should rather develop institutional policies to seek support and sponsorships from other sources (Oppenheim, 2008), and they should rely on voluntary cooperation by publishers, as is the case in countries like Portugal (Borbinha, 2004), The Netherlands, (Oltmans and Van Wijngaarden, 2006), Croatia, Norway and Denmark (Zivkovic, 2008), and Switzerland (Clavel-Merrin, 2010). The United Kingdom has legislation in place for the legal deposit of electronic books, but prefer to co-opt voluntary compliance of especially electronic publications (albeit offline) by publishers (Green, 2009). Canada, Denmark, Finland, France, Japan, Norway and South Africa have included legal deposit of electronic publications in their legislation (Larivière, 2000).

The challenge thus lies in lobbying and participating in the formulation and to establish an institutional policy that can direct supplementary means of support - and that can meet with national legislation if in place.

Developments in technology and the publishing industry also requires existing legislation to be revisited, because territoriality as claimant for legal deposit compliance becomes highly contentious when the electronic book exists exclusively, geographically independently “in the cloud” (Gibby and Green, 2008).

\subsection{Legal and ethical considerations}

Copyright, digital rights management and licensing issues are important issues for legal deposit of electronic books (Kumbhar, 2012). Copyright owners (e.g. authors, publishers) are apprehensive about the following: (i) the ease of copying material into machine-readable form; (ii) giving access to millions, and the (iii) difficulty to police this (Oppenheim, 2008). Legal considerations such as copyright, open access, ethical considerations, author's rights and intellectual property are thus important (Krynicka, 2012). Usually the intellectual rights of a publication reside with the creator of that information unless it changes ownership. 


\subsubsection{Copyright of Electronic Legal Deposit Publications}

Copyright has an undisputed influence on preservation and access of digital publications. Larivière (2000) states that copyright is the exclusive right of an author to decide on reproduction and dissemination. Legislation and licenses are usually the means through which permission for reproduction and dissemination is granted; intellectual rights are with the author / creator of information unless it changes ownership. According to Kumbhar (2012) copyright and digital rights management are issues that will still be discussed for years to come; if not addressed, copyright and intellectual property rights issues have the potential to prevent preservation (Moghaddam, 2010). On the other side of the coin users want free access to material without paying any money (Walsh, 2008): private copying allows the reproduction of a legally acquired work for personal use, but does not consider the exclusive copyright of an author (Schöpfel, 2006).

\subsubsection{Open Access}

Open access (OA) concerns the idea of unlimited, permanent and easy availability of the content of digital resources for free. It is mainly aimed at scientific and educational publications (Hockx-Yu, 2006). Taking the author's right into consideration, people can read, copy and cite in open access without any barriers (Krynicka, 2012). It is the author's decision if the publication will be available for open access or not (Prowse, 2006). Publishers contribute to the tenets of open access by developing a lot of different open access models and greater awareness for open access (Greig and Nixon, 2007).

Traditionally, legal deposit is of material that is not freely available and the depository has to protect the work of the author from piracy and copyright infringement as explained in section 3.3. Open access material on the other hand, is made freely available through the permission of the author/owner. Legal deposit material can only be accessed through the library, but open access material can be accessed from anywhere. Though freely available, open access material is still material that has been published, and needs to go through the same mechanisms for depositing as other material. This is very important to enhance effective organisation and access. As there are different open access models (Greig and Nixon, 2007), legal depositories should be aware of the model applied to specific material and whether any additional usage rights apply. They should also keep up to date with the developments in open access - and by implication electronic books in open access.

\subsubsection{Ethical Considerations}

The digital nature of electronic books, bring different legal and ethical questions into consideration. Access to electronic books is e.g. restricted for visually impaired users if text-to-audio functionality is not included in the Digital Rights Management (DRM) (Acedo and Leverkus, 2014). DRM has technical protecting measures through which the licensing terms is enforced and through which the use of electronic resources can be restricted (Gibby and Green, 2008). Privacy and confidentiality are also ethical issues to consider; usage of electronic books can e.g. be monitored with implications for the users (Mutula, 2014). Libraries handling legal deposit of electronic books need to be aware of the spectrum of ethical considerations. 


\subsection{Environmental factors}

Environmental factors include the physical environment and infrastructure. Facilities, furniture and buildings as such are not physical environmental issues limited to legal deposit, but might contribute to the success or failure of legal deposit. For electronic books environmental factors, such as ICT infrastructure and connectivity are very important - especially in developing countries (Chowdury, 2013), and specifically in Africa where poor telecommunication infrastructure and inadequate ICT training are listed as challenges for legal deposit (Matuvo and Musoke, 2012).

Physical access to legal deposit collections is usually limited to on-site only secure access in national libraries (Webb, Pearson and Koerbin, 2013). Users can then only read the printed books in the reference section of the library. Access to electronic books are however depending on electronic means on the library's computerised equipment such as computers, physical storage media (carriers such as DVD; external hard drives and USB sticks) and electronic readers (portable/handheld devices like Kindle; "smart" mobile phones; tablets; i-pads) (Oppenheim, 2008). All electronic access must be protected by authentication mechanisms and equipment must be configured to prevent piracy - which is a dire problem (Ibrahim and Edzan, 2004). It must also be configured to facilitate protection of intellectual material and copyright (Clausen, 2004), which, as already noted, is a serious problem.

The physical management of electronic books requires a robust ICT hardware infrastructure (servers, network links), equipment with proven reliability to manage the technical obsolescence inherent of a digital environment (Brindley, Muir and Probets, 2004) and appropriate software such as operating systems, electronic repository application programs and digital object identifier systems, and web browsers (Green, 2009). The lack of fast, reliable network connections and reliable electrical energy supplies are issues of concern especially in developing countries (Suleman, as cited in Chowdury, 2013).

Interoperability of the networked electronic environment allows better interactive cooperation, collaboration and resource sharing between the national library and its stakeholders and partners (Hockx-Yu, 2006). It is considerably easier and cheaper for publishers to provide the required copies of their published electronic books to the legal depositories than it is for printed books - the networked technology facilitates ease of access for submitters directly to the electronic repository, no extra workflows for printing, and shorter delays in making it publically visible in the national bibliographic database. Self-publishers in particular benefit from the electronic environment as a means of "do-it-yourself authoring, distribution, and retailing"(Brantley, 2012, p. 172), and as a means to comply with legal deposit requirements [4].

The challenge thus lies in acknowledging the environmental factors noted here that need to be addressed and may complicate legal deposit, namely, infrastructure to organise material, infrastructure to provide access, measures to deal with obsolescence, and interoperability. 


\subsection{Establishing mechanisms for depositing}

As mentioned earlier, the legal deposit process for depositing of printed books are well established through legislation but the same cannot be said for legal deposit of electronic publications (Stephens and Gibby, 2011). The process for the depositing of electronic books is as follows: identification, selective collection, accessioning and processing, metadata and bibliographic control and standards (adapted from Muir, 2001). Each of these holds challenges - as noted in some of the sections to follow.

\subsubsection{Identification}

In some countries - like The Netherlands - legal deposit is on a voluntary basis (Larivière, 2000). The onus then rests on national libraries and legal depositories to identify publications that should be in the legal depository. Various solutions have been offered. Webb, as cited in Muir (2001), argues that publishers need to register all their publications, but this is not a viable suggestion in the electronic environment. The sheer volume of electronic publications highlights the need for some means of unique identification for electronic publications (Moraru, 2013). There are, however, some limitations with existing mechanisms.

The International Standard Book Number (ISBN) cannot be used as unique identifier, because there may be several manifestations of the same book in different file formats. Thus another identifier must be used to distinguish between these different manifestations. Digital Object Identifiers (DOIs) and Uniform Resource Names (URNs) have been suggested in the identification of electronic books - "The DOI helps in the management and exploitation of digital information" and "URNs are persistent identifiers for online information" (Muir, 2001, p. 658;). Each DOI number is linked to one unique manifestation and thus serves the purpose of a unique identifier.

Another problem is that although bibliographic control is not as well established with electronic books as with printed formats, it is still very important (Zivkovic, 2008; Krynicka, 2012). Bibliographic control will be discussed as part of metadata.

\subsubsection{Selective collecting}

The Information Age, typified by the information explosion, introduced new challenges in terms of digital collections management (Enakrire and Onyenania, 2007). The volume of work that is being published is not the only challenge. The rise in independent authors and self-publishers, who publish exclusively through cloud-based (i.e. geographically independent) distributors and retail outlets such as Amazon, Aplle, Kobo, Barnes and Noble, and Smashwords (Brantley, 2012, p.174) poses a challenge to legal depositories who need to collect and preserve the material.

National libraries needed a paradigm shift, because building comprehensive collections of legal deposit material as mandated by legislation or agreement (Muir, 2001;) is no longer viable; in fact, the limitations of a depository's ability to capture and preserve publications (Muir, 2001, p. 655) may force national libraries to 
be selective in their collection of electronic books. This means they will need a collection policy and collection criteria.

Thus selective collection of electronic publications for legal deposit collections is based on quality judgements, for instance: the importance of a publication, its future value, and whether copyright allows access (Seadle, 2004). Vickery (2001, p. 302) recounts the British Library approach, i.e. that "accessibility, permanence and technical compatibility" must be part of the methodology for selection of publications for a legal deposit collection. These criteria can be further extended.

There are three main methods for supporting selective collection of electronic books for legal deposit: i) information can be transferred onto a physical medium by the publishers and sent to the repositories; ii) publishers can use networks to "push" information through to repositories; and iii) national libraries can collect freely accessible online publications (Zivkovic, 2008, p. 12), as well as search on publishers' websites, and "pulling" (i.e. harvesting) publications from the sites (Muir, 2001, p. 659). Harvesting is the term used when software is used to automatically extract information from the web (Krynicka, 2012).

\subsubsection{Accession and processing}

As with printed books, electronic books also need to be accessioned. All received items must go through quality checks and functional tests. These tests check for "correct version, required medium and format, completeness; undamaged; fully functional, error free and not copy protected" (Muir, 2001, p. 660). Digital documents can change very easily, and therefore it presents additional challenges in the digital environment to ensure authentication of digital documents (Muir, 2001). Repositories must be "verifying the integrity of ingoing and outgoing files", and "limit the processing of files, in order to keep costs down" (Oltmans and Van Wijngaarden, 2006, p. 606). A challenge to legal depositories is the increased workload in terms of the number of publications.

\subsubsection{Bibliographic control and metadata}

The processing of electronic books is done by bibliographic control. Good bibliographic control is important, because national bibliographies (capturing the national record of publications) need to have correct bibliographic information for others to verify against, e.g. correct personal names and translated works. Bibliographic control helps with distinction between different versions (hardcopy versus electronic copy) of the same book. Current cataloguing rules are, however, not adequate in describing electronic publications (Muir, 2001) and supporting the integration of electronic books into library catalogues (Day, 2007). Witt (2003, p. 384) questions the sufficiency of bibliographic descriptive components and iterates that value might be added by the inclusion of abstracts and tables of content.

The number of resources, including electronic books, available on the web continues to grow exponentially and with it the need to obtain more information about the resources that are available (i.e. a need for better bibliographic control). Using metadata can solve this problem. 
Metadata is "structured data that describes specific functions that may include resource discovery and access, collection management and resource evaluation, rights management and digital preservation" (Day, 2007, p. 35). It shows the creation details (how, why, and when), the intended purpose of the record, instructions on how to open and read the record, the terms of access (any restrictions or not), the migration history of the record and any changes made to it after it was created (was it scanned for example) (Mutula, 2014). A metadata standard for electronic documents is Dublin Core Metadata Element Set (DCMES), which consists of 15+ metadata elements and is used for - "enriching the descriptive, semantic and interoperability aspects of such resources" (Alijani and Jowkar, 2009, p. 441-442). Descriptive metadata, administrative (or technical) metadata and preservation metadata can be used (Alijani and Jowkar, 2009; Day, as cited in Groenewald and Breytenbach, 2011, p. 241). The latter is especially important for legal depositories and is discussed in a later section.

It is of utmost importance that metadata be implemented by both creators of digital objects, and those responsible for its accessibility and usability (Chowdury, 2013). For legal deposit of electronic books we need to extend the metadata currently assigned for books to metadata that will support electronic books (Otto, 2014).

\subsubsection{Standards}

There are many standards that affect electronic books and legal depositories. Standards such as the Open Archives Initiative Protocol for Metadata Harvesting (OAI-PMH), allow repositories to expose data for aggregation, exploration and sharing (Hockx-Yu, 2006), while ONIX (Online Information eXcbibliographic) is an international standard developed by the book trade for communicating product information in electronic form (Brindley, Muir and Probets, 2004). Although many standards have been developed, very few of them are, however, "stable and robust" (Brindle, Muir and Probets, 2004, p. 240).

Organizations such as the International Digital Publishing Forum endeavour to set standards for the creation, distribution and use of electronic books (Zivkovic, 2008), to ensure interoperability (Borbina, 2004), and for mapping programmes transforming MARC data into Dublin Core (Clavel-Merrin, 2014). Collaboration nationally and internationally between role players in setting up standards are, however, vital (Green, 2009). These can include companies that supply electronic book readers such as Kobo, Apple, Sony (Brantley, 2012); they seem to be a major influence currently in drawing up standards. Libraries, library schools and publishers can also be much more active in drawing up standards (Kumbhar, 2012). National libraries and legal depositories need to contribute.

\subsubsection{Information retrieval and access}

Accessing electronic books requires the actions of seeking, retrieving and locating information about electronic books (Clausen, 2004). Access to legal deposit collections are usually limited to on-site secure access in national libraries, as explained in an earlier section. Groenewald and Breytenbach (2011) argue 
that the increasing amount of stored information will have an influence on the speed of retrieving information and that appropriate and sufficient metadata can reduce retrieval time. The ability to perform searches over "diverse sets of metadata" is called interoperability (Caplan, as in Lopatin, 2006, p. 281). Furthermore, the inter-operability between the databases of legal depositories is very important for access to electronic books (Borbinha, 2004).

\subsubsection{Preservation of electronic books}

Long-term retention and -preservation are issues of major concern to institutions managing legal depositories. Technology obsolescence, caused by frequent hardware and software upgrades or replacements is frequently highlighted as a major challenge for institutions (Hockx-Yu, 2006). The problem is exacerbated by the data deluge caused by ease of creation, rapid developments in computing power, and increased network bandwidth (Kirchhoff, 2011).

Hockx-Yu (2006, p.234) furthermore pointed out that "the timeframe during which preservation [of digital material] must take place is much shorter than for printed material." Green (2009, p. 136) concurred: "the publishing process, from author through to reader, is now digital, or has the potential to be digital. In fact, many within the British Library are starting to consider that the print version is a surrogate for the digital original, rather than the other way round."

Although articles abound regarding the organisational, managerial and technological challenges for longterm preservation of digital material in general less has been published in the context of legal deposit and national libraries per se. In the United Kingdom Beagrie discussed the challenges to be faced by the British Library in 2001 (Beagrie, 2001). Woodyard (2004) and Green (2009) responded with strategies and programmes developed to overcome the obstacles. Portugal opted for strategies specific to relevant scenarios, rather than a complete model to encompass all the legal deposit issues (Borbinha, 2004). Van Wijngaarden (2007) reported on the preservation activities and projects of the European National Libraries as a group, and in 2013 Webb, Pearson and Koerbin discussed the concept of "statement of preservation intent" being implemented by the National Library of Australia.

Other issues of concern regarding digital preservation are:

- permanent access (e.g. Oltmans and Van Wijngaarden, 2004).

- long-term accessibility of the content (e.g. Hockx-Yu, 2006; Lopatin, 2006).

- safe storage - the terms long-term-, or archival storage in the context of preservation and archiving of legal deposit of e-publications are also used (e.g. Brindley, Muir and Probets, 2004).

- physical storage media, i.e. the

○ carrier (e.g. Moghaddam, 2010; Nsibirwa, Hoskins and Stilwell, 2014)

○ file format (e.g. Hockx-Yu, 2006).

- preservation metadata, which is crucial for preservation operations such as migration and repurposing 
(e.g. Moghaddam, 2010) and provide extensive detail on the subject.

Although there are many preservation strategies, two approaches are favoured to successfully address the issues of permanent access, safe storage and preservation metadata: (i) migration - simply saving a file in a new format, and (ii) emulation which is more complex, requiring emulation tools to preserve both the file in its original state, and the software / readers to access it (Green, 2009).

\subsection{Human resources}

Skilled human resources are also a challenge in legal deposit. In 2004 Borbinha (2004, p.19) already put the question: "Who will build and maintain this new [digital] library? Are we only going to have to rethink the traditional roles, or will we have to consider new ones?". Hockx-Yu (2006, p. 236) concurred: "Digital preservation requires new workflows, new skills and close co-operation across different professions ranging from traditional preservation management skills to computing science. The organisational structure to support this is not yet in place."

A study by Katuu (as cited in Wamuloya and Mutula, 2005, p. 72) reveals lack of knowledgeable and adequately trained staff, high staff turnover and lack of funds and human and physical resources as global problems that exist in many countries impacting on the production and collection of online information - and potentially also on legal deposit. Lopatin (2006, p. 275) concurs: "familiarity with resources in the collection, understanding the information needs of the clients and sensitivity to clients information seeking" is required, especially with regards to digital preservation where there can be multiple versions of an item, decisions about selecting which version to preserve and difficulties when there are more than one version that need to be kept - this requires special expertise (Moghaddam, 2010).

Organisations need adequate staff and systems to be able to fulfil their duties of collecting, managing, storing and preserving electronic publications as part of legal deposit (Cunningham, 2005). Effective access of electronic information is enhanced through information technology (IT) (Mutula and Makondo, 2003) and therefore a sound knowledge of IT and IT procedures are additional skills that are required for legal deposit of electronic books (Steenbakkers, 2002).

\subsection{Financial implications}

The initial cost of investment in the establishment of a legal deposit repository is very high in terms of human resources, ICT infrastructures, physical space as well as running- and maintenance costs (Oltmans and Van Wijngaarden, 2006). Smith (2008) iterated that financial sustainability relies on sources of funding and stakeholder buy-in. Thus institutions dependent on governments for financial support, must also invest in collaboration (e.g. consortia) and expansion of products and services to the international platform, e.g. subscribed public access to unique collections and content. 
Although archives and libraries at both national and local levels have a public duty to collect, maintain, and preserve material of historical interest, they often do not have a substantial additional budget with which to achieve this in a digital domain which commentators believe is growing exponentially year on year (Kurzweil, as cited in Spence, 2005). This adds to the pressure on national libraries to take on these duties.

\subsection{Trust}

"Trust is an issue that could become a significant barrier for institutional repositories and increase the complexity of digital preservation" (Hockx-Yu, 2006, p. 236). This also applies to national legal repositories, especially with regards to electronic books.

Mutual trust and confidence in each other are vital aspects of the relationships between legal depositories and publishers (Gibby and Green, 2008); between national libraries, their patrons and (to a certain extent) the ICT industry. Users need to trust the national libraries to guarantee long term access to the electronic cultural heritage of the nation (Hockx-Yu, 2006). They also need to trust that what has been made available for their perusal, would be as good as the original version and format submitted on legal deposit - these are complicated issues that touch on authentication and validation of different representations through digital certification (Walsh, 2008), as well as version migration and emulation for preservation (Green, 2009).

Publishers need to trust national libraries to protect their commercial interests (Oltmans and Van Wijngaarden, 2006) and to ensure long term preservation. In return national libraries must trust publishers to comply with legislation or agreements to submit all of their publications to complete the legal deposit collections. National libraries need to trust their governing bodies to preserve longevity (of both the institution and its legal deposit content) with financial sustainability (Hockx-Yu, 2006). It might be argued that the governing body in turn must trust the national library to manage the nation's cultural heritage with competency and trustworthiness (Hockx-Yu, 2006). Governments must ensure protection through policies and regulations, thus promoting further mutual trust between the legal depositories and publishers (Gibby and Brazier, 2012).

National libraries rely on technology for long term preservation, and thus need to trust it to ensure sustainable quality (Skarstein, 2010), despite fast technological obsolescence. Borbinha (2004) even asked whether legal depositories can trust the market, and expect mature and trustworthy products and technology. Liew (2009) researched issues of trust, authenticity and integrity, and concluded that many technologies are indeed available to assist in the digital preservation process, and can be readily integrated into an operational digital preservation framework - and thus helps in establishing trust. Although some guidelines have been published on this, more is required. 


\section{Conclusion}

National libraries embarking on projects on legal deposit of electronic publications and more specifically electronic books need to consider various aspects of the collection, preservation and accessibility of the legal deposit collection. Challenges that national libraries face in this regard include legal deposit legislation and institutional policy, environmental factors, established mechanisms for deposit, information retrieval and access, preservation, legal considerations, human resources, financial implications and trust. Some of these problems have been explored in this paper. However, continued monitoring and research of issues of concern and changes are required due to technological developments and the obsolescence of technology. Further research might especially be needed regarding the legal deposit of online books (i.e. books published exclusively on the world wide web), because its physical carrier or physical location, file formats and lack of appropriate metadata standards cause specific problems for legal depositories such as national libraries.

If one considers the issues and challenges discussed in this paper, the question has to be asked what this means for the future of legal deposit. Brantley (2012, p. 172) argues that the digital surge of self- and independent published digital literature poses a threat to the ability of national libraries "to collect and preserve a nation's written cultural or written heritage". Will the concept of legal deposit change or maybe even be ignored entirely? Are these issues created by technology simply one more challenge for legal depositories to overcome or is it time for the concept of legal deposit to be challenged? Will partnerships with archiving entities, such as Portico and LOCKSS, become necessary to preserve a country's cultural heritage?

Nsibirwa, Hoskins and Stillwell (2014, p. 62) notes that: "to ensure access for the future generations, legal depositories require a solid foundation from proper legislation, adequate funding, staff with preservation skills and knowledge, proper preservation policies, activities and strategies, as well as collaboration with other countries to look at a way forward with the preservation of electronic publications." This is especially relevant for developing countries, and in particular Africa "in the broader context of bridging the content divide in order to bequeath present and future generations the treasures of a nation for their socio-economic development' (Mutula, 2014, p. 363). It is hoped that this article will encourage national libraries to address the challenges and to get involved with further research.

\section{Notes}

[1] France has had a legal deposit law since 1537.

[2] There are 199 countries officially recognised by the United Nations. Many countries, also amongst those not officially recognised by the United Nations, have more than one national library. A list of national and state libraries is available from http://en.wikipedia.org/wiki/List_of_national_and_state_libraries.

[3] In many countries other institutions also act as legal deposit repositories, ensuring physical distribution of copies in case of disaster. 
[4] According to www.publishersweekly.com (28 July 2014) the Author's Earnings Report by Hugh Howley found that self-published books now represent $31 \%$ of e-book sales on Amazon's Kindle Store.

\section{REFERENCES}

Acedo, S. and Leverkus, C. (2014), "Updates on e-books: challenges and changes", Knowledge Quest, Vol. 43 No. 1 , pp. 44-52.

Alijani, A. and Jowkar, A. (2009), "Dublin Core Metadata Element Set usage in national libraries' web sites", The Electronic Library, Vol. 27 No. 3, pp. 441-447.

Ayre, C. and Muir, A. (2004), "The right to preserve: the rights issues of digital preservation", D-Lib Magazine, Vol. 10 No. 3, available at http://www.dlib.org/dlib/march04/ayre/03ayre.html (accessed 24 August 24 2014).

Beagrie, N. (2001), "Preserving UK digital library collections”, Program, Vol. 35 No. 3, pp. 217-226.

Bhatti, M.W. (2014), "National Library of Pakistan as legal depository", Pakistan Library and Information Science Journal, Vol. 45 No. 1, pp. 18-23.

Borbinha, J. (2004), "An approach to creating a national digital library", International Journal on Digital Libraries, Vol. 4 No. 1, pp. 19-22.

Bothmann, R. (2004), “Cataloging electronic books”, Library Resources and Technical Services, Vol. 48 No. 1 , pp. $12-20$.

Brantley, P. (2012), "The new missing books", Publishing Research Quarterly, Vol. 28, pp. 172-175.

Brindley, G., Muir, A. and Probets, S. (2004), "Provision of digital preservation metadata: a role for ONIX?", Program: electronic library and information system, Vol. 38 No. 4, pp. 240-250.

Caplan, P. (2004), "Building a digital preservation archive: tales from the front”, VINE: The Journal of Information and Knowledge Management Systems, Vol. 34 No. 1, pp. 38-42.

CDNL - Conference of Directors of National Libraries. (2012), "E-legal deposit", available at http://www.cdnl.info/Legal_Deposit/CDNL\%20advocacy\%20document_1.pdf, (accessed 22 July 2014.

Chowdury, G. (2013), "Sustainability of digital information services", Journal of Documentation, Vol. 69 No. 5, pp. 602-622. 
Clausen, H. (2004), "Intellectual property, the internet and the libraries”, New Library World, Vol. 105 No. 1206/1207, pp. 417-422.

Clavel-Merrin, G. (2010), "Many roads to information: digital resource sharing and access at the Swiss National Library", Interlending and Document Supply, Vol. 38 No. 1, pp. 54-57.

Cunningham, A. (2005), "Accountability and accessibility: ensuring the evidence of e-governance in Australia", Aslib Proceedings: New Information Perspectives, Vol. 57 No. 4, pp. 301-317.

Day, M. (2007), "Resource discovery, interoperability and digital preservation: some aspects of current metadata research and development", VINE: The Journal of Information and Knowledge Management Systems, Vol. 29 No. 4, pp. 35-48.

Diemeka, A. (2012), "Multilinguality in the digital library: a review", The Electronic Library, Vol. 30 No. 2, pp. 165-181.

Enakrire, T. and Onyenania, O. (2007), "Causes inhibiting the growth or development of information transfer in Africa: a contextual treatment", Library Hi Tech News, Vol. 4, pp. 20-28.

Gibby, R. and Brazier, C. (2012), "Observations on the development of non-print legal deposit in the UK", Library Review, Vol. 61 No. 5, 362-377.

Gibby, R. and Green, A. (2008), "Electronic legal deposit in the United Kingdom", New Review of Academic Librarianship, Vol. 14, pp. 55-70.

Green, S. (2009), "The digital library programme at the British Library: goals and priorities", Interlending and Document Supply, Vol. 37 No. 3, pp. 136-139.

Greig, M.G. and Nixon, W.J. (2007), "On the road to Enlighten-ment": establishing an institutional repository service for the University of Glasgow", OCLC Systems \& Services: International Digital Library Perspectives, Vol. 23 No. 3, pp. 297-309.

Groenewald, R. and Breytenbach, A. (2011), "The use of metadata and preservation methods for continuous access to digital data", The Electronic Library, Vol. 29 No. 2, pp. 236-248. 
Hockx-Yu, H. (2006), "Digital preservation in the context of institutional repositories", Program: Electronic Library and Information Systems, Vol. 40 No. 3, pp. 232-243.

Hormia-Poutanen, K., Kautonen, H. and Lassila, A. (2013), "The Finnish National Digital Library: a national service is developed in collaboration with a network of libraries, archives and museums. Insights", Vol. 26 No. 1 , pp. 60-70.

Ibrahim, S. and Edzan, N.N. (2004), "Legal deposit of electronic publications in Malaysia: 1988-2000", Malaysian Journal of Library and Information Science, Vol. 9 No. 2, pp. 63-78.

Kirchhoff, A. (2011), "eBooks: the preservation challenge”, Against the Grain, Vol. 23 No. 4, pp. 32-34. Kiteley, R. and Stogdon, C. (2014), Literature Reviews in Social Work, Sage: London.

Krishnamurthy, M. (2008), "Open access, open source and digital libraries: a current trend in university libraries around the world", Program: Electronic Library and Information Systems, Vol. 42 No. 1, pp. 48-55.

Krynicka, M. (2012), “Open access to national bibliography: Polish approach”, Collection Building, Vol. 31 No. 3, pp. 120-125.

Kumbhar, R. (2012), "E-books: review of research and writing during 2010", The Electronic Library, Vol. 30 No. 6, pp. 777-795.

Larivière, J. (2000), Guidelines for Legal Deposit Legislation, United Nations Educational, Scientific and Cultural Organization: Paris.

Liew, C.I. (2009), "Digital library research 1997-2007: organisational and people issues”, Journal of Documentation, Vol. 65 No. 2, pp. 245-266.

Lopatin, L. (2006), “Library digitization projects, issues and guidelines: a survey of the literature”, Library Hi Tech, Vol. 24 No. 2, pp. 273-289.

Lor, P. (2005), "Preserving African digital resources is there a role for repository libraries?", Library Management, Vol. 26 No. 1/2, pp. 63-72.

Matovu, J. and Musoke, W. (2012), "Impact of the new legal deposit system on national bibliographic control in Uganda: practices, developments and challenges", Library Philosophy and Practice, available at http://unllib.unl.edu/LPP/, (accessed 24 August 2014). 
Moghaddam, G. (2010), "Preserving digital resources: issues and concerns from a view of librarians", Collection Building, Vol. 29 No. 2, pp. 65-69.

Moraru, A. (2013), "The National Library of Romania and its patrimony function”, Romanian Journal of Library and Information Science, Vol. 9 No. 2, pp. 14-16.

Muir, A. (2001), "Legal deposit and preservation of digital publications: a review of research and development activity", Journal of Documentation, Vol. 57 No. 5, pp. 652-682.

Mutula, S. (2014), "Status of digital heritage preservation management in Eastern Africa", The Electronic Library, Vol. 32 No. 3, pp. 363-374.

Mutula, S. and Makondo, F. (2003), "IT skills needs for collection development at the University of Botswana Library", Library Hi Tech, Vol. 21 No. 1, pp. 94-101.

Nsibirwa, Z., Hoskins, R. and Stilwell, C. (2014), "Building the South African Nation through legal deposit: the impact of legislation on preservation of digital materials", African Journal of Library, Archives and Information Science, Vol. 24 No. 1, pp. 53-65.

Oltmans, E. and Van Wijngaarden, H. (2004), "Digital preservation in practice: the e-Depot at the Koninklijke Bibliotheek", VINE: The Journal of Information and Knowledge Management Systems, Vol. 34 No.1, pp. 21-26.

Oltmans, E. and Van Wijngaarden, H. (2006), "The KB e-Depot digital archiving policy", Library Hi Tech, Vol. 24 No. 4, pp. 604-613.

Oppenheim, C. (2008), "Legal issues for information professionals IX : an overview of recent developments in the law, in relation to the internet", Journal of Documentation, Vol. 64 No. 6, pp. 938-955.

Otto, J. (2014), "Administrative metadata for long-term preservation and management of resources", Library Resources and Technical Services, Vol. 58 No. 1, pp. 4-32.

Prowse, S. (2006), "Recent developments in remote document supply in the UK - 2", Interlending \& Document Supply, Vol. 34 No. 3, pp. 125-131.

Saarti, J. and Vattulainen, P. (2013), "Management of and access to print collections in national and repository libraries in Europe: collection for use or for preservation”, Library Management, Vol. 34 No. 4/5, pp. 273-280. 
Schöpfel, J. (2006), "The new French law on author's rights and related rights in the information society", Interlending and Document Supply, Vol. 34 No. 4, pp. 167-170.

Seadle, M. (2004), "Selection for digital preservation”, Library Hi Tech, Vol. 22 No. 2, pp. 119-121.

Skarstein, V.M. (2010), “The Bookshelf: digitisation and access to copyright items in Norway”, Program: Electronic Library and Information Systems, Vol. 44 No. 1, pp. 48-58.

Smith, K. (2008), “Institutional repositories and e-journal archiving: what are we learning?", Journal of Electronic Publishing, Vol. 11 No. 1, pp. 1-10.

Spence, J. (2005), “Small organisations and cultural institutions - a digital future?", Program: Electronic Library and Information Systems, Vol. 39 No. 4, pp. 366-380.

Steenbakkers, J. (2002), "Preserving electronic publications”, Information Services and Use, Vol. 22, pp. 8996.

Stephens, A. and Gibby, R. (2011), "National implementations of electronic legal deposit", Alexandria, Vol. 212 No. 1 , pp. 53-67.

Van Wijngaarden, H. (2007), "Update on long-term preservation activities and projects in European national libraries", International Preservation News, Vol. 42, pp. 4-7.

Vassiliou, M. and Rowley, J. (2008), "Progressing the definition of "e-book"”, Library Hi Tech, Vol. 26 No. 3, pp. 355-368.

Vattulainen, P. (2004), "National repository initiatives in Europe", Library Collections, Acquisitions, \& Technical Services, Vol. 28, pp. 39-50.

Vickery, J. (2001), "Reorganization in the British Library to acquire electronic resources", Library Collections, Acquisitions, \& Technical Services, Vol. 25, pp. 299-305.

Walsh, J. (2008), "Who will be responsible? The authentication and preservation of government digital information", Library Hi Tech News, Vol. 9, pp. 22-25.

Wamuloya, J. and Mutula, S. M. (2005), "Capacity-building requirements for e-records management: The case in East and Southern Africa", Records Management Journal, Vol. 15 No. 2, pp. 71-79. 
Webb, C., Pearson, D. and Koerbin, P. (2013), “'Oh, you wanted us to preserve that?!' statements of preservation intent for the National Library of Australia's Digital Collections", D-Lib Magazine, Vol. 19 No. 1/2, available at http://www.dlib.org/dlib/january13/webb/01webb.html (accessed 24 August 2014).

Witt, M. (2003), "Bibliographic description of electronic resources and user needs", Online Information Review, Vol. 27 No. 6, pp. 383-395.

Woodyard, D. (2004), "Significant property: digital preservation at the British Library", VINE: The Journal of Information and Knowledge Management Systems, Vol. 34 No. 1, pp. 17-20.

Yoon, H.Y., Oh, S.K. and Kim, S.Y. (2008), "Shortage of storage space in Korean libraries: solutions centering upon hub-based collaborative repositories", Aslib Proceedings: New Information Perspectives, Vol. 60 No. 3, pp. 265-282.

Zivkovic, D. (2008), "The electronic book: evolution or revolution?" Information World / Biligi Dunyasi, Vol. 9 No. 1, pp. 1-19. 